\title{
Forrageamento de Melissoptila thoracica Smith (Hymenoptera, Eucerini, Apoidea) em flores de Sida (Malvaceae)
}

\author{
Viviane da Silva-Pereira1, Isabel Alves-dos-Santos 2, \\ Kátia Sampaio Malagodi-Braga ${ }^{3} \&$ Felipe Andrés Leon Contrera ${ }^{3}$
}

\author{
1 Programa de Pós-Graduação em Botânica, Departamento de Ciências Biológicas, Universidade Estadual de Feira de \\ Santana. Rodovia BR 116, Km 03, Campus Universitário, 44031-460 Feira de Santana, Bahia, Brasil. \\ 2 Diretoria de Pós Graduação, UNESC. Caixa Postal 3167, 88806-000 Criciúma, Santa Catarina, Brasil. \\ ${ }^{3}$ Laboratório de Abelhas, Departamento de Ecologia, Instituto de Biologia, Universidade de São Paulo. Rua do Matão 321 , \\ Travessa 14, Cidade Universitária, 05508-900 São Paulo, São Paulo, Brasil.
}

\begin{abstract}
Foraging behavior of Melissoptila thoracica Smith (Hymenoptera, Eucerini, Apoidea) on flowers of Sida (Malvaceae). Foraging activity of a solitary bee species - Melissoptila thoracica Smith, 1854 (Eucerini) - was studied considering its phenology, floral preferences, foraging patterns and pollen's transportation structures. $M$. thoracica females present a clear preference for flowers of Sida Linnaeus (Malvaceae) in relation to pollen collection. The fidelity for the plant was observed considering foraging flights and analyzing the pollen carried in the females' scopes. The collection of pollen by bees was estimated throughout the counting of remaining grains in the anthers, over one and three visits. Females were examined in scanning electronic microscopy for the analysis of pollen grains in the ventral pilosity and in the scopes. M. thoracica was considered an effective pollinator of Sida flowers.
\end{abstract}

KEY WORDS. Food source, oligolectic, pollen transportation, solitary bee, weed plants.

Recompensas florais podem ser consideradas quaisquer componentes da flor ou inflorescência utilizadas por animais. Devido às recompensas, as flores asseguram visitas repetidas que levam à polinização. Entre os agentes polinizadores, as abelhas merecem papel de destaque devido entre outros fatores, à diversidade do grupo e à dependência de pólen e néctar para sua sobrevivência (BAWA 1990).

Para a coleta de pólen as abelhas exibem diferentes comportamentos que estão diretamente associados ao padrão floral, ao tipo de deiscência e à morfologia da flor (RoubiK 1989). Em geral as abelhas têm maior especificidade em relação à coleta de pólen do que de néctar e quando restringem suas coletas a uma ou poucas espécies de plantas relacionadas, elas são chamadas de abelhas oligoléticas (Linsley 1958). Na maioria das vezes esta restrição é acompanhada por adaptações morfológicas e/ou comportamentais das abelhas (e.g. NeFF \& SIMPSON 1993, Alves dos Santos 1998, Schlindwein 1998).

Estudos anteriores relataram o comportamento oligolético de algumas espécies de abelhas do gênero Melissoptila Holmberg, 1884 (Eucerini) em relação a plantas da família Malvaceae, em especial do gênero Sida Linnaeus. Morato \& CAmpos (2000) avaliaram a partição de recursos florais de várias espécies de Sida entre Melissoptila cnecomala (Moure, 1944) e Cephalurgus anomalus Moure \& Oliveira, 1962 em Viçosa, Minas Gerais. Gaglianone (2000) estudou a biologia floral de 17 espécies simpátricas de Malvaceae (sendo 11 espécies de Sida) e suas abelhas visitantes, entre elas três espécies de Melissoptila em Ribeirão Preto, São Paulo.

Neste trabalho acompanhou-se o comportamento de Melissoptila thoracica Smith, 1854 durante visita às flores de Sida, e investigou-se a preferência floral desta espécie, bem como o comportamento de coleta dos recursos alimentares nestas flores e as estruturas para transporte do pólen.

\section{MATERIAL \& MÉTODOS}

Este estudo foi realizado no jardim do Instituto de Biociências na Cidade Universitária em São Paulo (IBUSP) situado a $23^{\circ} 33^{\prime} \mathrm{S} / 46^{\circ} 43^{\prime} \mathrm{W}$. As observações do comportamento de visita foram feitas diretamente nas flores nos meses de verão (dezembro a fevereiro) por duas temporadas (1998/1999 e 1999/2000).

Melissoptila thoracica é uma espécie de porte médio com faixas de pêlos brancos nos tergos e densa pilosidade. Os machos são facilmente reconhecidos, até mesmo durante o vôo, por 
apresentarem antenas mais longas, manchas amarelas no clípeo, no labro e nas mandíbulas, e pilosidade fulva no tórax. Para o acompanhamento da atividade nas flores foram marcadas 36 abelhas (25 fêmeas e 11 machos). As marcações foram feitas com tintas coloridas (não tóxicas) sobre o tórax das abelhas previamente submetidas à baixa temperatura por 1-2 minutos. No vôo de forrageamento acompanhou-se a seqüência de flores visitadas, o tempo de visita em cada flor, o material coletado e o comportamento de coleta. As flores foram etiquetadas para acompanhamento da antese da flor e estimativa da retirada de pólen pelas abelhas.

Amostras de pólen foram retiradas das escopas de 14 fêmeas e preparadas em lâminas por acetólise, seguindo metodologia proposta por ERDTMAN (1960). Para cada amostra foram confeccionadas duas lâminas e cerca de 1.000 grãos foram contados, quando possível, em cada uma delas. Em seguida, os valores obtidos nas contagens dos grãos foram corrigidos pelo coeficiente de correção volumétrica (Q) de Tasei (SILveIra 1991) e a contribuição relativa de cada espécie vegetal foi estimada através da percentagem de representação.

Para a estimativa da retirada de grãos de pólen da flor durante visita das abelhas, foram preparadas 12 lâminas com pólen coletado das anteras das duas espécies de Sida L. Estimouse a quantidade de pólen presente em cada flor e a quantidade de pólen retirada após uma e três visitas das fêmeas de $M$. thoracica.

Para melhor entendimento do arranjo da carga de pólen presente no corpo das abelhas, as fêmeas de $M$. thoracica foram examinadas em microscópio eletrônico de varredura (MEV). Os exemplares de abelhas coletados foram depositados na coleção do Laboratório de Abelhas (IB/USP) e exsicatas das plantas foram depositadas no Herbário do Instituto Botânico de São Paulo (IBt).

\section{RESULTADOS}

\section{Fenologia da abelha e planta}

Melissoptila thoracica apresentou uma ocorrência sazonal bem nítida em São Paulo. O período de atividade se dá nos meses mais quentes do ano, entre novembro e fevereiro. Os primeiros indivíduos começam suas atividades em meados de novembro, com um máximo de indivíduos ativos em janeiro, sofrendo um declínio gradual entre o final de fevereiro e o início de março. A atividade de vôo de $M$. thoracica se dá entre 9:00 e 14:00 h.

Duas espécies de Sida ocorrem simultaneamente no jardim do Instituto de Biociências: Sida rhombifolia L. e S. planicaulis Cav. Os indivíduos das duas espécies podem ser diferenciados, em campo, pela coloração dos estiletes e estigmas, comprimento do pedúnculo floral, características do caule e horário de abertura das flores. Em Sida rhombifolia as pétalas são creme amareladas, os estiletes e estigmas vermelhos, e o caule ramificado. Nas flores de Sida planicaulis as pétalas são amarelas, os estiletes e estigmas amarelos e o caule plano e pouco ramificado. Os pedúnculos florais em $S$. rhombifolia são mais longos que $S$. planicaulis. Existe uma assincronia no período de antese entre as duas espécies: as flores de $S$. rhombifolia abrem às 9:00 $\mathrm{h}$ e fecham às 11:30 h, enquanto as flores de $S$. planicaulis estão abertas entre 11:30 e 14:00 h. As flores permanecem abertas apenas por 2-3 horas e enrolam as pétalas após este período. Os frutos estão formados após 10 ou 15 dias da queda da corola.

\section{Preferência floral e comportamento de coleta de Melis- soptila thoracica.}

Fêmeas de $M$. thoracica demonstraram uma clara preferência pelas flores das duas espécies de Sida para a coleta de pólen. As fêmeas procuram e visitam as flores de Sida antes mesmo de estarem completamente abertas. Quando isso acontece, promovem ou aceleram o processo de abertura da flor. Durante a visita, a fêmea pousa sobre as pétalas contatando as estruturas reprodutivas com a parte ventral do seu corpo, principalmente do tórax e região anterior do abdômen (Fig. 1). Ao pousar, inicia imediatamente um giro de $360^{\circ}$ em torno das anteras e dos estigmas. Com as pernas anteriores e médias coleta ativamente os grãos de pólen e em seguida transfere-os para as escopas das pernas posteriores.

Durante a visita às flores de Sida as fêmeas também executam movimentos de coleta de néctar forçando a cabeça e peças bucais para baixo, porém verificou-se que as flores de Elephantopus sp. (Asteraceae) são utilizadas como fonte adicional de néctar, já que as flores de Sida produzem quantidades tão ínfimas de néctar que não puderam ser quantificadas.

De um total de 16 vôos de forrageamento acompanhados, em $12(75 \%)$ as fêmeas visitaram exclusivamente flores de $S$. rhombifolia e $S$. planicaulis, e nos quatro restantes (25\%) realizaram vôos mistos, visitando flores das duas espécies de Sida e de Elephantopus sp. Durante estas obsevações as fêmeas de $M$. thoracica visitaram um total de 395 flores, das quais 69 (ca. $17,5 \%$ ) foram de Elephantopus. Para os machos, todos os vôos de forrageamento observados $(\mathrm{n}=9)$ foram mistos e Elephantopus sp. representou $66,8 \%$ das flores visitadas $(\mathrm{n}=217)$.

As fêmeas de $M$. thoracica permanecem cerca de 5 segundos nas flores de Sida $(\mathrm{n}=78)$ e quatro segundos nas flores de Elephantopus sp. $(\mathrm{n}=19)$. Durante um vôo de forrageamento as fêmeas despendem aproximadamente dois minutos e 30 segundos e visitam cerca de 24 flores $(\mathrm{n}=16)$, sendo o valor máximo de flores visitadas em um único vôo igual a 54 .

Os machos patrulham nas flores de Sida à procura das fêmeas para cópula e durante a patrulha, visitam as flores de Sida para tomar néctar. E, mesmo com visitas curtas e com movimentos rápidos, o pólen é aderido ao seu corpo.

\section{Carga polínica das fêmeas}

As amostras de pólen transportado pelas fêmeas de $M$. thoracia apresentaram grãos de pólen de $S$. rhombifolia e $S$. planicaulis (Malvaceae) e Elephantopus sp. (Asteraceae). O pólen de Sida se distingue facilmente na amostra devido ao seu tamanho (considerado grande) e ornamentação com espinhos bastante conspícuos, porém não há características evidentes que diferenciem os grãos das duas espécies de Sida estudadas. Por sua vez, o pólen de Elephantopus sp., como de muitas Asteraceae, é pequeno e bem característico. A tabela I apresenta a representação percentual dos grãos de pólen encontrados nas escopas das fêmeas de $M$. thoracica. Das 14 fêmeas examinadas, três apresentaram $100 \%$ pólen de Sida em seus carregamentos, enquanto em outras sete estes grãos exibiram uma representação superior a 97\% e em apenas 4 fêmeas esta representatividade foi inferior a $45 \%$ (Tab. I). Considerando-se todas as amostras nas quais os dois tipos polínicos (Sida e Elephantopus) estiveram presentes, a representação percentual de Elephantopus sp. foi de apenas $9,4 \%$ do total de grãos de pólen contados e corrigidos pelo coeficiente de Tasei. 

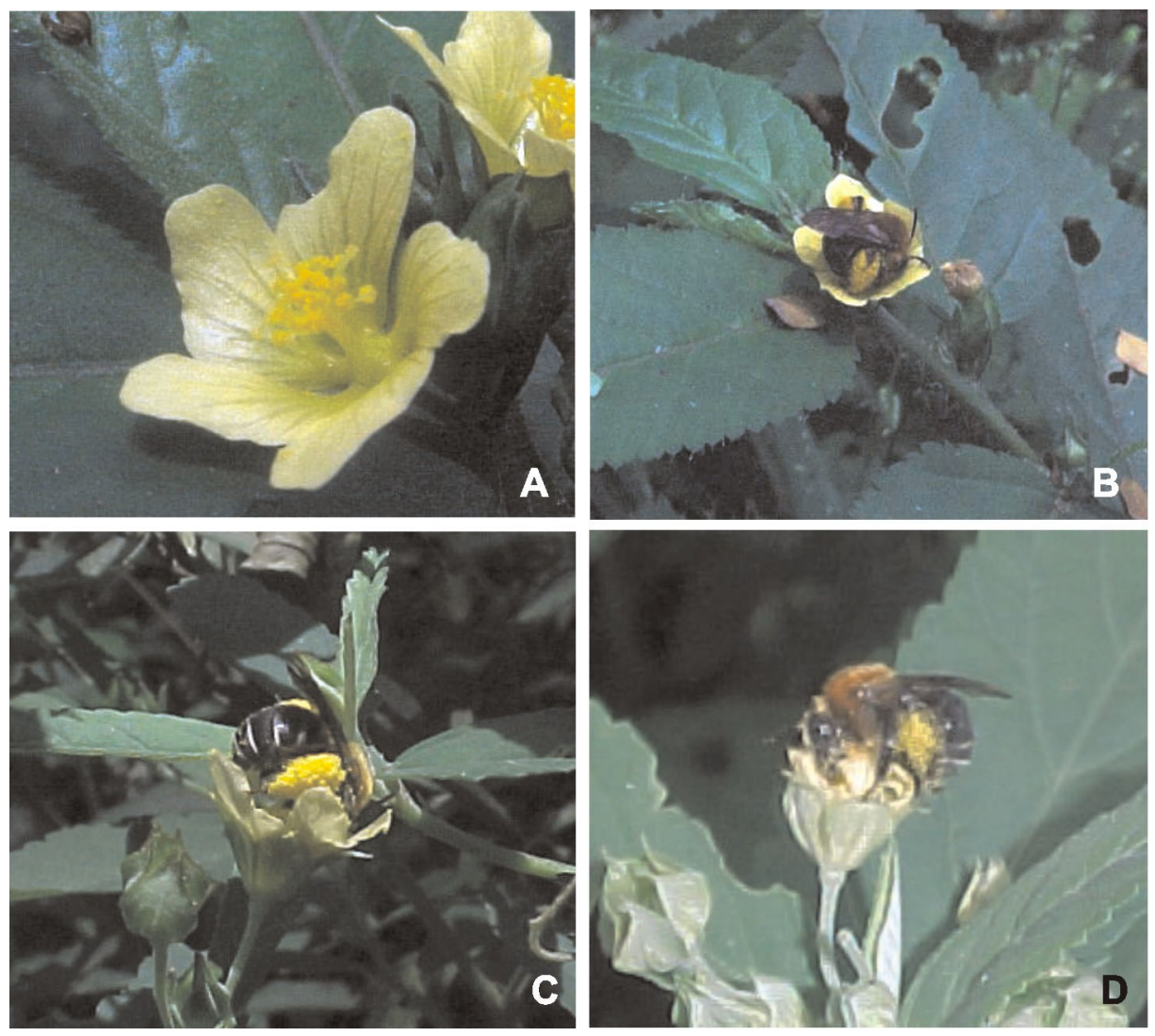

Figura 1. Seqüência da visita de Melissoptila thoracica à flor de Sida: (A) flor de S. planicaulis recém aberta; (B) chegada da fêmea de M. thoracica à flor de S. rhombifolia e início do giro de $360^{\circ}$; (C) coleta de pólen com o primeiro par de pernas; (D) transferência do pólen para as escopas.

Grãos de pólen de outras espécies de plantas, não identificadas, também foram encontrados nas amostras das escopas das fêmeas de $M$. thoracica. Esses grãos não foram considerados quanto à sua contribuição percentual na carga de pólen devido a sua ocorrência esporádica e em quantidade insuficiente para a realização dos cálculos do coeficiente de Tasei. Além disso, durante todo o período de estudo, as fêmeas de $M$. thoracica não foram observadas visitando outras flores que não fossem de Sida rhombifolia, S. planicaulis e Elephantopus sp.

\section{Retirada de pólen das flores de Sida e transporte dos grãos}

As flores de $S$. rhombifolia possuem 23 estames e disponibilizam cerca de 800 (mínimo 552, máximo1173, n = 12) grãos de pólen. Por sua vez, $S$. planicaulis possui 18 estames e cerca de 600 (mínimo 486, máximo 882, n =12) grãos de pólen. A partir destes valores, constatou-se que as fêmeas de $M$. thoracica retiram grandes quantidades de pólen a cada visita (Tab. II). Após uma visita restam menos do que 30\% dos grãos de pólen nas flores de $S$. planicaulis. Este valor se aproxima de $20 \%$ após três visitas da abelha nas flores de S. rhombifolia.

A maior parte do pólen retirado é armazenada na escopa das tíbias posteriores das fêmeas de $M$. thoracica. Na figura 2 (A-D) observa-se esta estrutura em dois momentos: limpa, quando a fêmea inicia o percurso de coleta; e carregada, após várias visitas às flores, estando evidente a homogeneidade da massa de pólen de Sida e o arranjo destes grãos que permanecem presos entre os pêlos. As cerdas possuem ramificações em suas extremidades que facilitam a fixação dos grãos. Parte do pólen também é transportada no segundo e no terceiro pares de coxas que possuem densa pilosidade e trocanteres posteriores com pêlos longos e curvos (Fig. 2F). Na porção ventral do tórax e abdômen das fêmeas, vários grãos de pólen também ficam aderidos durante o forrageamento nas flores. Este padrão de fixação de pólen na região ventral também foi observado nos machos de M. thoracica.

\section{DISCUSSÃO}

Muitas espécies de Malvaceae são consideradas plantas daninhas e infestantes bastante comuns devido à ocupação pioneira em ambientes perturbados (LorENZI 1991). Plantas do gênero Sida por exemplo, infestam freqüentemente lavouras, jardins, pastagens e terrenos baldios; podendo ser consideradas plantas invasoras altamente competitivas devido ao seu profundo sistema radicular. A taxa de propagação e o sucesso reprodutivo dessas plantas, de um modo geral, são altos em diversos 

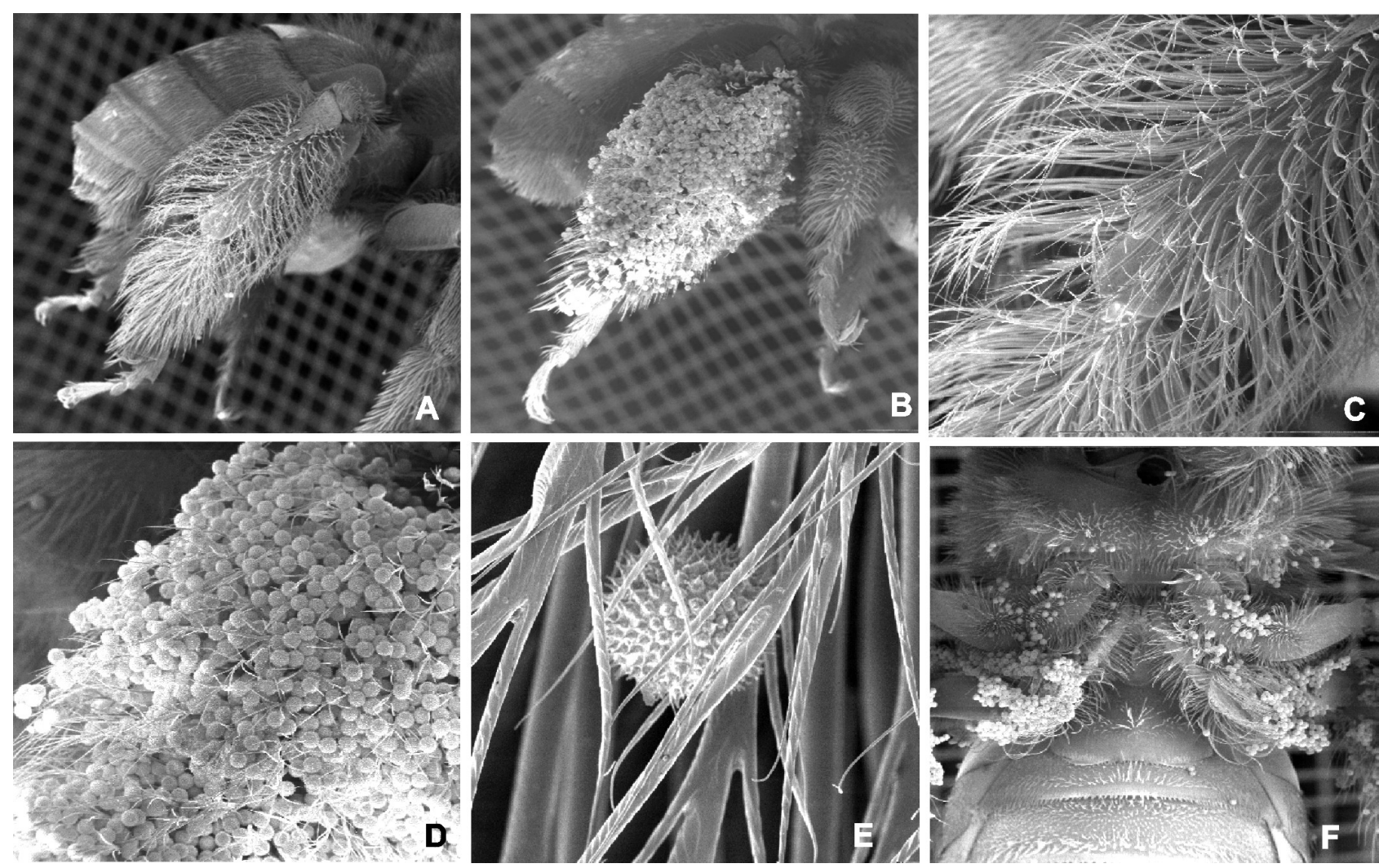

Figura 2. Imagens em microscopia eletrônica de varredura de fêmea de Melissoptila thoracica. (A-D): escopa na perna posterior limpa com as ramificações dos pêlos visíveis ( $A$ e $C$ ), carregada (B e D), observe a homogeneidade da massa de pólen; ( $E$ ) grão de pólen de Sida (grande e com espinhos) preso entre a pilosidade; (F) adesão de grãos de pólen na pilosidade ventral.

ambientes, demonstrando assim, uma reprodução independente de agentes polinizadores especializados (GAGLIANONE 2000). Apesar do caráter infestante, alguns autores alertam para o fato das floras ruderais serem ricas em elementos néctar-polinífero constituindo importante fonte alimentar para abelhas nativas principalmente em áreas degradadas (KerR 1968, Petanidou \& Smets 1995, Saure 1996, Nogueira-Neto 1997). No local estudado, no jardim do Instituto de Biociências, as duas espécies de Sida demonstraram ser a principal fonte polínica para as abelhas da espécie $M$. thoracica. Apesar da vasta oferta de flores encontradas no local de estudo, fêmeas de $M$. thoracica demonstraram clara preferência por flores de Sida rhombofolia e $S$. planicaulis. A presença de pólen de Elephantopus sp. no carregamento da escopa de algumas fêmeas foi interpretada como contaminação durante as visitas para coleta de néctar nesta Compositae.

Estudos anteriores também demonstraram a preferência floral de outras espécies de Melissoptila por flores de Malvaceae (Camargo \& Mazucato 1984, Silveira et al. 1993, Alves dos Santos 1999, Gaglianone 2000) e Laroca (1970) relatou visitas de $M$. thoracica em flores de Sida carpinifolia no Paraná. Morato \& CAmpos (2000) acompanharam o padrão da antese de várias espécies de Sida, relacionando-o ao padrão temporal de visita e partição dos recursos destas plantas pelos visitantes. Entre os visitantes, Melissoptila cnecomala, foi responsável por quase 50\% das visitas, retirando néctar e pólen das flores. No caso estudado, M. thoracica foi o visitante exclusivo das flores de Sida no jardim do IB-USP e praticamente $100 \%$ da retirada do pólen pode ser atribuída a esta espécie.

Segundo Goulson (1999) a decisão do visitante em manter a constância floral é complexa e está baseada em muitos fatores como, por exemplo, a habilidade e manuseio da flor e a detecção visual do recurso. Segundo ele, os recursos recebidos também determinam o modelo espacial da procura. Assim, a distância e a direção dos vôos são ajustados de tal modo que o forrageador tenda a permanecer dentro de uma certa área com recursos. No caso estudado, as fêmeas de $M$. thoracica exploraram a mesma área de recursos com bastante fidelidade. Isso foi possível detectar através das fêmeas marcadas. Aparentemente não existe uma rota de vôo ou territorialidade das fêmeas atuantes, mas possivelmente os recursos recebidos estão sendo suficientes para a população local de abelhas.

\section{Melissoptila thoracica como potencial polinizador}

Apesar da reprodução independente de agentes polinizadores (Lorenzi 2000), as duas espécies de Sida presentes no 
Tabela I. Representação percentual, após a correção pelo coeficiente de Tasei, do pólen presente nas escopas de 14 fêmeas de $M$. thoracica em São Paulo.

\begin{tabular}{cccc}
\hline \multirow{2}{*}{ Amostra } & \multicolumn{2}{c}{ Percentagem de grãos (\%) } & No. de grãos de pólen \\
\cline { 2 - 3 } & \multicolumn{1}{c}{ Sida } & Elephantopus & $\begin{array}{c}\text { Nontados por amostra } \\
\text { conn }\end{array}$ \\
\hline 1 & 100,0 & 0 & 139 \\
2 & 99,7 & 0,3 & 362 \\
3 & 44,7 & 55,2 & 1092 \\
4 & 99,4 & 0,6 & 73 \\
5 & 99,7 & 0,3 & 178 \\
6 & 44,3 & 55,7 & 1214 \\
7 & 42,7 & 57,3 & 1271 \\
8 & 97,8 & 2,2 & 976 \\
9 & 99,3 & 0,7 & 675 \\
10 & 97,3 & 2,7 & 1138 \\
11 & 100,0 & 0 & 1000 \\
12 & 25,9 & 74,1 & 1500 \\
13 & 100,0 & 0 & 1000 \\
14 & 97,0 & 3,0 & 1144 \\
\hline
\end{tabular}

Tabela II. Número de grãos de pólen presentes em cada antera das duas espécies de Sida antes da antese e após visita de Melissoptila thoracicia. Para cada amostra foram examinados 12 estames.

\begin{tabular}{lccc}
\hline \multirow{2}{*}{ Espécie de Sida } & \multicolumn{3}{c}{ Fase da flor } \\
\cline { 2 - 4 } & Botão & Após uma visita & Após três visitas \\
\hline S. rhombifolia & $31,5 \pm 6,88$ & $19,5 \pm 6,04$ & $7,0 \pm 3,23$ \\
S. planicaulis & $41,0 \pm 3,78$ & $11,0 \pm 6,32$ & valor não obtido \\
\hline
\end{tabular}

jardim do IB-USP podem estar se beneficiando da presença de $M$. thoracica para a transferência efetiva do pólen. No presente estudo, esta espécie de abelha demonstrou ser altamente especializada em flores de Sida e capaz de promover a polinização cruzada em função de sua alta fidelidade, constância floral, comportamento durante visita e padrão da pilosidade corpórea.

O período de abertura das flores de Sida rhombofolia e $S$. planicaulis, entre 9:00 e 14:00 h, coincide com o período de atividade diária de $M$. thoracica, no local estudado. As duas espécies de Sida são simpátricas, porém apresentam assincronia no período de antese. Gaglianone (2000) e Morato \& Campos (2000) acompanharam o padrão de antese de várias espécies de Malvaceae e destacaram a ocorrência de assincronia de abertura floral e antese entre as espécies. Estes autores sugerem que esta assincronia diminui a competição entre os polinizadores, pois evita a mistura de pólen entre as diferentes espécies de plantas e garante a troca dos gametas promovida pelo mesmo polinizador. No caso das duas espécies de Sida estudadas, as flores são muito semelhantes em termos de tamanho, forma e cor das pétalas, e poderiam ser visitadas na mesma rota de vôo de uma fêmea. Se estivessem abertas sincronicamente, uma mistura de pólen poderia ocorrer. Assim, a abertura e fechamento das flores em horários distintos, mas subseqüentes, protege as plantas de uma possível mistura de pólen, e garante a visita das abelhas sem interrupção do seu período de atividade.

Apesar da alta fidelidade de M. thoracica às flores de Sida spp. no local estudado, deve-se ressaltar que os grãos de pólen presentes nas escopas das tíbias posteriores não estão disponíveis para a polinização, pois não contatam os estigmas das flores. Por sua vez, o pólen aderido à pilosidade ventral da fêmea serve perfeitamente para promover a polinização cruzada da planta já que está em posição adequada de contato com o estigma durante a visita da abelha. Desta maneira, acredita-se que os machos também possam promover, com eficiência, a polinização dessas plantas, pois carregam pólen em partes semelhantes do corpo.

\section{Morfologia da escopa de M. thoracica e sua relação com o pólen de Malvaceae}

A localização, o tamanho e plumosidade das cerdas nas escopas, bem como o espaçamento entre elas, variam de acordo com o grupo taxonômico de abelhas e podem estar associados ao tamanho, formato e ornamentação dos grãos de pólen que carregam (RoBERTS \& VALLESPIR 1978, THORP 1979). De acordo com RoberTs \& VALLESPIR (1978), grãos de pólen grandes apresentam óleos na superfície, que auxiliam sua adesão aos pêlos das abelhas, que são lipofílicos. Além disso, estes autores afirmam que os espinhos formam séries de concavidades na superfície esferoidal do pólen. Desta maneira, acredita-se que além do óleo, os espinhos característicos dos grãos de pólen de Malvaceae auxiliam sua fixação nas escopas de M. thoracica. Em uma outra espécie de Melissoptila visitante de flores de Sida, M. bonaerensis Holmberg 1903, constatou-se padrão semelhante de arranjo e adesão dos grãos de pólen (IAS observação pessoal). As cerdas escopais longas, ramificadas e espaçosas das espécies de Melissoptila especializadas em Sida estão bem adaptadas para transportar os grãos de pólen grandes e espinhosos.

\section{CONCLUSÃO}

Considera-se que no local estudado as duas espécies de Sida são de fundamental importância para o sucesso reprodutivo de Melissoptila thoracica. As flores de Sida devem garantir alimento para a prole de $M$. thoracica e portanto sua reprodução. Por sua vez, através da elevada freqüência de visita, da alta fidelidade e do comportamento nas flores, essas abelhas devem contribuir para a polinização cruzada e formação de sementes das espécies de Sida estudadas. Mesmo não dependendo da ação de polinizadores para se propagar, a troca gamética entre os indivíduos de Sida pode ser promovida por fêmeas e machos de $M$. thoracica, beneficiando assim o aumento da taxa heterozigose nas sementes destas plantas.

\section{AGRADECIMENTOS}

Gostaríamos de agradecer a Vera Lúcia Imperatriz Fonseca pelas idéias e incentivo desde o início deste trabalho; ao Laboratório Abelhas da USP pelo apoio logístico; ao Laboratório de Microscopia Eletrônica da USP pela confecção das imagens em MEV, em especial Márcio C. Valentim; a Danúncia Urban (UFPR) pela identificação da espécie Melissoptila thoracica; 
Gerleni Lopes Esteves (IBt/SP) pela identificação das plantas; e a Denise A. Alves pelo auxílio nas observações. Ao CNPq/PIBIC pelo suporte financeiro à FALC. Dedicamos este trabalho ao Professor Jesus Santiago Moure, pela passagem do seu nonagésimo aniversário no dia 02 de novembro de 2002.

\section{REFERÊNCIAS BIBLIOGRÁFICAS}

Alves dos Santos, I. 1998. A importância das abelhas na polinização e manutenção da diversidade dos recursos vegetais. Anais III Encontro sobre Abelhas de Ribeirão Preto, Ribeirão Preto, 3: 101-106.

_ 1999. Abelhas e plantas melíferas da Mata Atlântica, restinga e dunas do litoral norte do Estado do Rio Grande do Sul, Brasil. Revista Brasileira de Entomologia, Curitiba, 43 (Supl. 3/4): 191-223.

BAWA, K.S. 1990. Plant - pollinator interactions in tropical rain forests. Annual Review of Ecology Systematics, Palo Alto, 21: 399-422.

Camargo, J.M.F. \& M. Mazucato. 1984. Inventário da apifauna apícola de Ribeirão Preto, SP, Brasil. Dusenia, Curitiba, 14 (2): 55-87.

ErdTMAN, G. 1960. The acetolysis methods. A revised description. Svensk Botanisk Tidskrift, Stockholm, 54 (4): 561-564.

Gaglianone, M.C. 2000. Biologia floral de espécies simpátricas de Malvaceae e suas abelhas visitantes. Biociências, Porto Alegre, 8 (1): 13-31.

Goulson, D. 1999. Foraging strategies of insects for gathering nectar and pollen, and implications for plant ecology and evolution. Perspectives in Plant Ecology, Evolution and Systematics, Jena, 2: 185-209.

KerR, W.E. 1968. Comece certo com as abelhas. Coopercotia, São Paulo, 221, p. 28-36.

LARoCA, S. 1970. Notas adicionais sobre a bionomia das espécies de Melissoptila que ocorrem nas vizinhanças de Curitiba, Paraná (Hymenoptera, Apoidea). Boletim da Universidade Federal do Paraná, série Zoologia, Curitiba, 15: 293-306.

LinsLey, E.G. 1958. The ecology of solitary bees. Hilgardia, Berkeley, 27 (19): 543-597.

LoRENZI, H. 1991. Plantas daninhas no Brasil - terrestres, aquáticas, parasitas, tóxicas e medicinais. Nova Odessa, Ed. Plantarum Ltda. $2^{\mathrm{a}}$ ed., 440p.

- 2000. Manual de Identificação e Controle de Plan- tas Daninhas. Nova Odessa, Ed. Plantarum Ltda. $5^{\mathrm{a} e d .,}$ 300p.

Morato, E.F. \& L.A.O. Campos. 2000. Partição de recursos de Sida Linnaeus e Malvastrum coromandelianum (Linnaeus) Garcke (Malvaceae) entre Cephalurgus anomalus Moure \& Oliveira (Hymenoptera, Andrenidae, Panurginae) e Melissoptila cnecomala (Moure) (Hymenoptera, Apidae, Eucerini). Revista Brasileira de Zoologia, Curitiba, 17 (3): 705-727.

Neff, J.L. \& B.B. Simpson. 1993. Bees, Pollination Systems and Plant Diversity, p. 143-167. In: J. LASALLE \& I.D. GAuld (Eds). Hymenoptera and Biodiversity. Wallingford, $C A B$ International, 348p.

Nogueira-Neto, P. 1997. Vida e criação de abelhas indígenas sem-ferrão. São Paulo, Nogueirapis, 446p.

Petanidou, T \& E. Smets. 1995. The potential of marginal lands for bees and apiculture: nectar secretion in Mediterranean shrublands. Apidologie, Le Ulis, 26: 39-52.

RoberTS, R.B. \& S.R. VALLESPIR. 1978. Specialization of hairs bearing pollen and oil on legs of bees (Apoidea: Hymenoptera). Annals of Entomological Society of America, Lanham, 71 (4): 619-627.

RoubiK, D.W. 1989. Ecology and natural history of tropical bees. New York, Cambridge University Press, 514p.

SAURE, C. 1996. Urban habitats for bees: the example of the city of Berlin. p 47-54. In: A. Matheson; S.L. BuchmanN; C. O'Toole; P. Westrich \& I.H. Willians (Eds). The conservation of bees. New York, Academic Press, 254p.

SCHLINDWEIN, C. 1998 Frequent oligolecty characterizing a diverse bee-plant community in a xerophytic bushland of subtropical Brazil. Studies on Neotropical Fauna \& Environment, Lisse, 33: 46-59.

SilveirA, F.A. 1991. Influence of pollen grain volume on the estimation of the relative importance of its source to bees. Apidologie, Le Ulis, 22: 495-502.

Silveira, F.A; L. Rocha Lima; M.J.F. Oliveira \& J.R. Cure. 1993. Abelhas silvestres (Hymenoptera, Apoidea) da zona da mata de Minas Gerais II. Diversidade, abundância e fontes de alimento em uma pastagem abandonada em Ponte Nova. Revista Brasileira de Entomologia, Curitiba, 37 (3): 595-610.

THorp, R.W. 1979. Structural, behavioral, and physiological adaptations of bees (Apoidea) for collecting pollen. Annals of the Missouri Botanical Garden, St. Louis, 66: 788-812.

Recebido em 09.I.2003; aceito em 13.VIII.2003. 